\title{
SOBRE LA DETERMINACION DE PENA Y EL RECURSO DE NULIDAD EN LA LEY 20.084 SOBRE RESPONSABILIDAD PENAL ADOLESCENTE ${ }^{\circ}$
}

\author{
Gonzalo Medina Schulz.
}

\begin{abstract}
1. Introducción; 2. La determinación de penas en el Derecho Penal chileno: i. Aspectos dogmáticos; ii. El sistema legal general, en especial el contenido del artículo 69 y la valoración de las circunstancias modificatorias; 3. Las particularidades de la determinación de penas en materia de responsabilidad penal juvenil: $i$. El sistema de sanciones en la Ley 20.084; ii. La determinación de penas en el artículo 24: a) El catálogo de sanciones en la $\operatorname{LRP} A$; b) El deber de expresión de los criterios en la sentencia: $i$. Los criterios del articulo 24: a) La infracción al ne bis in idem; b) La elección de la clase de sanción; c) El análisis de los criterios: c.1. La gravedad del ilicito de que se trate; c.2. La calidad en que el adolescente participó en el hecho y el grado de ejecución de la infracción; c.3. La concurrencia de circunstancias atenuantes o agravantes de la responsabilidad criminal; c.4. La edad del adolescente infractor; c.5. La extensión del mal causado con la ejecución del delito; c.6. La idoneidad de la sanción para fortalecer el respeto del adolescente por los derechos y libertades de las personas y sus necesidades de desarrollo e integración social: 4. El recurso de nulidad ante la determinación de penas en la Ley $N^{\circ}$ 20.084: $i$. El recurso de nulidad y la violación de las reglas de determinación de pena en el Derecho Penal: a) La casación en materia penal y la jurisprudencia sobre infracción de las normas; b) El recurso de nulidad por infracción del artículo 24 de la Ley 20.084: b.1. La falta de fundamentación como causal; b.2. La infracción de derecho; b.3. La extensión de la revisión; b.4. La resolución de la nulidad; 5. Consideraciones finales.
\end{abstract}

\section{Introducción ${ }^{1}$}

Una de las cuestiones fundamentales introducidas a propósito del nuevo régimen de responsabilidad penal adolescente en Chile se refiere al sistema de sanciones aplicables a los ilícitos cometidos por menores infractores de ley. En efecto, la Ley $\mathrm{N}^{\circ} 20.084$ que establece un sistema de responsabilidad penal de los adolescentes por infracciones a la ley penal, en adelante LRPA, contempla diversas formas de sanciones, que permiten dar un tratamiento diferenciado respecto a la responsabilidad penal de adultos.

Las materias aquí abordadas pertenecen al amplio abanico de temas a los que Juan Bustos realizó contribuciones esenciales ${ }^{2}$, tanto en su labor parlamentaria,

\footnotetext{
${ }^{\circ}$ El presente corresponde a un Informe en Derecho para la Unidad de Defensa Penal Juvenil de la Defensoría Penal Pública (Documento de Trabajo N ${ }^{\circ}$ 14).

* Profesor invitado de Derecho Penal, Universidad de Chile.

1 El autor agradece especialmente los comentarios formulados a una versión preliminar de éste trabajo por don Gonzalo Berríos, doña Alejandra Díaz, don Alejandro Gómez y don Fernando Mardones, todos ellos de la Defensoría Penal Pública.
} 
Medina - Sobre la determinación de pena y el recurso de nulidad...

en su actividad docente y en su trabajo académico. Es por ello que se elije este texto para un homenaje a uno de los penalistas más trascendentes de nuestro país y que en el amplio espectro de temas que abordo, nos dejo un legado difícilmente superable, pero que el derecho penal del adolescente encuentra un campo fértil de trabajo.

Ha de tenerse presente que la cuestión de determinación de pena y su revisión mediante el recurso de nulidad es un asunto cuya respuesta depende de diversos supuestos. En primer término, de un análisis de los presupuestos de la determinación de penas en general, como fenómeno clave del Derecho Penal, del cual la LRPA es sólo un caso de regulación especial. Enseguida, es necesario detenerse en consideraciones generales del sistema de determinación de pena en su regulación positiva, a efecto de establecer cuáles son las particularidades del mismo.

Establecidas las consideraciones que la materia posee en el Derecho Penal en sentido amplio, corresponderá el análisis de la revisión de los elementos de la determinación de pena en la LRPA, para lo cual se ha de contextualizar éste tanto en el sistema de sanciones que establece el mencionado cuerpo legal como en el marco de lo dispuesto por el artículo 24 de la correspondiente ley. En ese contexto, se hace especial hincapié en el examen de los criterios que en concreto dispone la ley para su consideración y valoración al momento de determinar la pena concreta a imponer.

El segundo paso se refiere a la posibilidad de revisión de las sentencias, por cuestiones vinculadas al problema de la determinación de pena. Al igual que en el apartado anterior, previo al análisis de las cuestiones referidas a la LRPA se analiza el aspecto como un problema general del Derecho Penal y Procesal Penal, para lo cual se expone el estado actual de la discusión dogmática y jurisprudencial. En particular, ese análisis requiere de una breve exposición de las cuestiones referidas al recurso de casación y su procedencia respecto a la determinación de pena, para después revisar esos criterios a la luz de la regulación del recurso de nulidad.

Finalmente, se revisarán las causales del recurso de nulidad y sus relaciones con los aspectos relevantes del sistema de determinación de pena contemplado en la LRPA, de tal manera de establecer en qué casos y qué causales podrían dar lugar a un recurso de nulidad en la materia.

\footnotetext{
${ }^{2}$ A mero modo ejemplar ha de citarse la obra directamente vinculada con el tema aquí expuesto: Bustos, Juan, El derecho penal del niño-adolescente: estudio de la ley de responsabilidad penal del adolescente, EJS, 2007
} 


\section{La determinación de penas en el Derecho Penal chileno}

La cuestión sobre determinación de pena en el Derecho chileno obedece a un doble sistema, de determinación legal de marcos y determinación judicial de la pena concreta a aplicar, momento en el cual tanto la clase de sanción como su extensión son elementos sobre los cuáles ha de reflexionarse. El sistema de determinación de pena obedece al juego de diversos factores que permiten llegar desde el marco que en la parte especial se establece para una conducta ilícita determinada hasta la pena concreta, expresada habitualmente en cantidades, sea de días de privación de libertad, total o parcial, o privación de otros derechos, sea en sumas de unidades de valor, que finalmente se impone a un sujeto por un hecho determinado. La aplicación fundada de esas reglas en la sentencia constituye el proceso de determinación judicial de la pena, también conocido como individualización de la misma.

Los factores que inciden en la determinación judicial de la pena aplicable dicen relación con diversos elementos: el juicio de subsunción de la conducta bajo una norma penal determinada, el establecimiento del grado de ejecución de la conducta, el establecimiento del grado de participación que le cabe al sujeto y, finalmente, la aplicación de las reglas de determinación de pena en sentido estricto.

Esas reglas están contempladas en nuestro Código Penal en los artículos 65 y siguientes, disposiciones que están estrechamente ligadas con aquellas de los artículos 62 y siguientes del Código Penal. Es indudable que las normas sobre determinación de pena constituyen normas de carácter jurídico, cuya vulneración en principio daría lugar a la procedencia de un recurso de nulidad. Ello sin embargo parece enfrentarse con un problema conceptual arraigado en nuestra praxis judicial, que consideraría que la "discrecionalidad" judicial en la determinación de la pena concreta significa el otorgamiento de una facultad que puede ejercerse arbitrariamente por parte del juez. Esta arbitrariedad tendría dos consecuencias: (i) la posibilidad de establecer la concurrencia de causales de modificación de la responsabilidad penal y, en especial, sus consecuencias, sin expresión de fundamentos; (ii) la ausencia de un control de derecho estricto sobre las decisiones que sobre esa base adopten los tribunales.

Ambas premisas bajo las cuales opera la determinación de pena en nuestro derecho han transformado a esta etapa de la atribución de responsabilidad por hechos ilícitos en el espacio predilecto de la arbitrariedad judicial, de forma tal que, con prescindencia de los esfuerzos dogmáticos a fin de refinar el proceso de subsunción de un comportamiento bajo una determinada norma penal, el resultado concreto se puede ver notoriamente alterado de acuerdo a la aplicación que de esas disposiciones efectúen los tribunales. La facultad judicial de determinar la pena concreta es invaluable y, por cierto, irrenunciable. Sin embargo, ella no puede convertirse en el vehículo predilecto del decisionismo contra-legislativo. 
Medina - Sobre la determinación de pena y el recurso de nulidad...

\section{i. Aspectos dogmáticos}

La discusión sobre determinación judicial de la pena constituye sin duda uno de los aspectos más problemáticos y, a la vez, más descuidados de la dogmática penal. Ella se ha concentrado más bien en las etapas de determinación legal, subsunción en un tipo penal, grado de ejecución y participación, que en la búsqueda de parámetros que permitan orientar al juez al momento de imponer una pena concreta, en virtud de un hecho determinado. Lo anterior se ve claramente agravado en sistemas como el chileno, en el cual el lapso que abarcan las penas privativas de libertad puede ser muy extenso, de cinco años en los casos de la pena de presidio mayor, con lo cual los márgenes decisorios entregados al órgano judicial son extremadamente amplios. Sin perjuicio de ello, la determinación de pena sigue siendo un aspecto del Derecho penal material ${ }^{3}$, que como veremos no puede entenderse sin referencia a las reglas de la teoría del delito y sus consecuencias.

En este sentido se afirma correctamente que "reducir la teoría penal sólo a la teoría del delito y del sujeto responsable, es una forma de encubrimiento que impide ver la realidad del sistema penal ..."4, por lo que a esta teoría ha de dotársele de un desarrollo dogmático tan intenso como aquél que ha experimentado la teoría del hecho punible. Al fin y al cabo, tan o más importante que el título de incriminación y la atribución de responsabilidad a un sujeto por un suceso criminal, es la fijación de un quantum de pena que en el caso concreto corresponde.

De igual manera, la vinculación entre praxis de determinación de pena y actividad legislativa es evidente, pues mediante la técnica de los delitos cualificados y privilegiados el legislador va desarrollando criterios similares a los de la determinación judicial, pero fijando sus consecuencias, de manera que siempre existe una relación dinámica entre la determinación legal y la judicial.

Las teorías sobre la determinación de la pena se han vinculado tradicionalmente a dos aspectos: los fines de la pena y el concepto de culpabilidad, como límite del reproche penal. En ese contexto se ha desarrollado la teoría del ámbito de juego (Spielraumtheorie), desarrollada por la jurisprudencia alemana, que se traduce en la determinación de límites mínimos y máximos de la pena, al interior de los cuales el juez puede operar orientándose a los fines legítimos de la pena ${ }^{6}$. En esta tesis los límites mínimos y máximos siempre están determinados por la pena

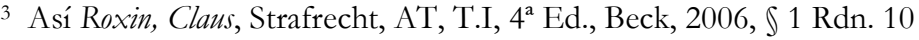

4 Bustos, Juan, Obras Completas, Derecho Penal, Parte General, EJS, 2007, p. 436.

5 Con detalle, ya advertido en Schröder, Horst, Gesetzliche und richterliche Strafzumesung, en: Engisch/Maurach, (Eds.) Festschrift für Edmund Mezger, C.H. Beck, Münich, 1954, p. 413 ss.

6 Vid. Ziffer, Patricia, Lineamientos de la determinación de la pena, Ad-Hoc, Buenos Aires, 1996, p. 49; Streng, \46, Rdn. 97. en: Kindahäuser, Urs/ Neumann, Ulfrid/Paeffgen, Hans-Ullrich (Eds.), Nomos-Kommentar zum Strafgesetzbuch. $2^{a}$ ed., Baden-Baden: Nomos Verlag, 2005, citado en adelante $\mathrm{NK} /$ autor.
} 
adecuada a la culpabilidad, no debiendo el juez jamás imponer una pena que exceda el merecimiento por la culpabilidad ${ }^{7}$. Sin embargo, la teoría del ámbito de juego no permite solucionar los problemas de discrecionalidad en la determinación de pena ${ }^{8}$, con lo cual sólo permiten excluir los casos más evidentes de penas que exceden el marco de la culpabilidad, pero no entrega criterios para eliminar la discrecionalidad en la generalidad de los casos.

A la teoría del ámbito de juego se le opone la denominada teoría de la pena puntual (Punktstrafetheorie), la cual postula que para cada caso determinado sólo existe una determinada pena correcta ${ }^{9}$, que sólo no puede ser conocida en virtud de los defectos cognitivos humanos ${ }^{10}$. Esta propuesta parece acercarse más a la determinación conforme a la culpabilidad, pero su pretensión es, por una parte irrealizable, por la otra, conduce a consecuencias indeseadas en el plano procesal. En el primer sentido, la teoría de la pena puntual desconoce la imposibilidad, más allá de las posibilidades humanas, de clasificar y valorar diferenciadamente todos y cada uno de los posibles resultados y variaciones de los tipos penales, así como de su traducción en valores numéricos ${ }^{11}$. La segunda objeción se verifica al revisar las posibilidades de revisión judicial de la determinación de pena, la cual se transforma en infinita e incontrolable, al establecer un criterio de determinación con tal pretensión de exactitud.

Como alternativa de la teoría del ámbito de juego se ha desarrollado también la teoría del valor relativo (Stellenwerttheorie), que a través de una parcialización del proceso de determinación de pena, considera que en la fijación del quantum de la sanción ha de atenderse exclusivamente a la culpabilidad por el hecho, siendo esto una cuestión necesariamente previa. Acto seguido, al momento de determinar la clase de sanción y su ejecución se deben atender a los fines preventivos $^{12}$. Esta teoría enfrenta críticas desde el punto de vista del texto legal alemán, que reclama la orientación a fines en la determinación de la entidad de la sanción aplicable, pues ya en ese momento deben considerarse los efectos de la pena para la futura vida en sociedad del condenado, según reza el $₫ 46 \mathrm{StGB}^{13}$.

\footnotetext{
7 Cfr. Schaffstein, Friedrich, Spielruam-Theorie, Schuldbegriff und Strafzumessung nach den Strafrechtsreformgesetzen, en: Lackner et. al (Eds.) Festshcrift für Wilhelm Gallas, Walter de Gruyter, Berlin, 1973, p. 99.

8 Ziffer, Patricia, Lineamientos de la determinación de la pena, p. 50.

9 Ziffer, Patricia, Lineamientos de la determinación de la pena, p. 51; NK/ Streng, \46, Rdn. 104.

${ }^{10}$ Schaffstein, Friedrich, Spielruam-Theorie, Schuldbegriff und Strafzumessung nach den Strafrechtsreformgesetzen, p. 100 s.; Hörmle, Tatjana, Tatproportionale Strafzumessung, Duncker \& Humblot, Berlin, 1999, p. 157.

11 Vid. Hörnle, Tatjana, Tatproportionale Strafzumessung, p. 158.

12 Ziffer, Patricia, Lineamientos de la determinación de la pena, p. 51; NK/ Streng, \ 46, Rdn. 106.

13 A ello se ha respondido con una teoría del valor relativo preventivo-especialmente modificada que acepta consideraciones de prevención general positiva en el momento de la determinación de la entidad de la sanción, lo cual contradice en si los postulados esenciales de la teoría del valor relativo cfr. NK/Streng, \ 46, Rdn. 108.
} 
Medina - Sobre la determinación de pena y el recurso de nulidad...

En el marco de la teoría de la determinación de la pena concurren actualmente dos marcadas orientaciones. Una de ellas ve en la cuestión de la determinación de pena una concretización de la teoría de los fines de la pena ${ }^{14}$. La mencionada posición en la teoría de la determinación de pena, que aboga por la aplicación de los criterios derivados desde la teoría de la pena, se puede reconducir ya al trabajo señero en la materia de $S p e n d e l^{15}$, el cual postula que el fin de la pena es el fundamento final de la determinación de pena. Desde esa concepción, la individualización de la pena es un fenómeno que depende del establecimiento previo de los fines de la sanción penal, de los cuales la individualización no sería sino su concreción en el caso particular.

Así, "la ponderación de los fines preventivos de la sanción penal pertenece a la naturaleza de la individualización y exige una valoración de tales fines en sus proyecciones para el caso concreto, que complementa la apreciación abstracta realizada por el legislador." ". Para ello se argumenta, en referencia al artículo 69 del Código Penal, que su interpretación debe hacerse en clave preventiva, pues de lo contrario existe el riesgo de caer en una vulneración del ne bis in idem ${ }^{17}$.

Sin embargo, no puede negarse a la teoría de la determinación de pena en clave de orientación a los fines de la pena, aún cuando se opte por una teoría preventiva de la misma, una vinculación con el principio del hecho, como elemento rector del reproche penal a imponer ${ }^{18}$. Junto a ello, no es posible vislumbrar cómo se solucionan los conflictos con el ne bis in idem, sólo porque las circunstancias relevantes para la determinación de la pena sean consideradas globalmente, esto es, no en su efecto particular, sino como una consideración a la apreciación conjunta de ellas. Ese procedimiento no permite refinar la pena que ha de determinarse, sino que sólo introduce mayores espacios de arbitrariedad. En el caso de una valoración global, de todas formas vuelve a existir una nueva valoración cuya infracción del mencionado principio no se hace evidente, por lo difuso que resulta esa consideración general de las circunstancias modificatorias.

\footnotetext{
14 En ese sentido expresamente Feijoo, Bernardo, Retribución y Prevención General, B. de F., 2007, p. 677.

15 Spendel, Günther, Zur Lehre vom Strafmaß, Klostermann, 1954.

16 Van Weęl, Alex, Determinación de la pena exacta: El artículo 69 del Código Penal, Ius et Praxis, Año 7, $\mathrm{N}^{\circ}$ 2, p. 403.

17 Van Weezl, Alex, Determinación de la pena exacta: El artículo 69 del Código Penal, Ius et Praxis, Año 7, $\mathrm{N}^{\circ}$ 2, p. 403. La vinculación entre teoría de la pena y teoría de la determinación de pena es un punto controvertido, adhiriendo algunos a la diferenciación entre uno y otro plano, así Demetrio Crespo, Eduardo, Prevención general e individualización judicial de la pena, Ediciones Universidad de Salamanca, 1999, p. 48 ss.. Crítico al planteamiento de Crespo vid. Feijoo, Bernardo, Individualización de la pena y teoría de la pena proporcional al hecho, In-Dret, $\mathrm{N}^{\circ} 1,2007$, p. 11 ss.

18 Crítica a una perspectiva judicial en la determinación de la pena enfocada a criterios de prevención vid. García Aran, Mercedes, La prevención general en la determinación de la pena, ADPCP, 1981, p. 510 ss. La autora argumenta en contra de esta utilización con base en la clásica crítica al utilitarismo que subyace a todas las teorías relativas de la pena, op. cit. 519 ss.
} 
Entre nosotros, algunos autores han tomado postura al respecto. Así, Van Weeze $l^{19}$ manifiesta su opción por una teoría de la determinación de la pena que pone acento en las funciones de la pena como criterio esencial de la interpretación y aplicación de los factores que inciden en la determinación de la misma. En ese sentido se han expresado también Horvitr. ${ }^{20}$ y Cillero $^{21}$, autores que abogan, la primera por el criterio de la prevención especial positiva como determinante en el sentido de la LRPA, el segundo por una aplicación de las reglas de determinación de pena orientada hacia la idea de una teoría de los fines de la pena de corte integradora, sin perjuicio de abogar por una pena determinada con vista a la culpabilidad por el hecho ${ }^{22}$. En el Derecho Penal en general también es posible encontrar posturas inclinadas más bien a la idea de prevención general negativa ${ }^{23}$.

La otra tesis en discusión actual, denominada generalmente neoproporcionalismo o teoría de la determinación de pena proporcionada al hecho (Tatproportionale Strafzumessung) intenta una interpretación de las reglas de determinación de pena orientada no a las consecuencias preventivas, sino al hecho realizado ${ }^{24}$. Esta orientación se prefiere aquí, cuestión que es de importancia, pues la adopción de una u otra tesis sobre la determinación de pena conduce a significativos efectos en el marco de la interpretación y aplicación de las reglas de determinación de pena en el Derecho Penal, en general, y en la LRPA.

Por otra parte, la teoría de la determinación de pena proporcional al hecho plantea que los criterios han de orientarse al establecimiento de una pena adecuada al hecho cometido por el autor, antes que a la búsqueda de la pena más adecuada para lograr efectos en el propio autor o en terceros ${ }^{25}$, y que en buena parte surge

19 Van Weezl, Alex, Determinación de la pena exacta: El artículo 69 del Código Penal, Ius et Praxis, Año 7, N², p. 401 ss.

20 Horvitz Lennon, María Inés, Determinación de las sanciones en la ley de responsabilidad penal juvenil y procedimiento aplicable, Documento de Trabajo $\mathrm{N}^{\circ} 1 / 2006$, Unidad de Defensa Penal Juvenil, p. 5, quién sin perjuicio de atribuir importancia a factores retributivos, sostiene la preponderancia de la finalidad preventivo-especial.

21 Cillero, Miguel, Consideraciones para la aplicación del criterio de idoneidad en la determinación de las sanciones en el Derecho Penal de Adolescentes Chileno, Documento de Trabajo No 13, 2008, Unidad de Defensa Penal Juvenil, p. 17.

22 Cillero, Miguel, Consideraciones para la aplicación del criterio de idoneidad en la determinación de las sanciones en el Derecho Penal de Adolescentes Chileno, p. 23.

23 Rudnick Vizcarra, Carolina, La compensación racional de circunstancias modificatorias en la determinación de la pena, Lexis Nexis, 2007, p. 484 ss.

24 En esa línea recientemente Silva Sánchez, Jesús $M$. La teoría de la determinación de la pena como sistema (dogmático): un primer esbozo, In-Dret, 2007, p. 1 ss.

25 Ello parte de una actualización de la concepción del rol de la culpabilidad en la determinación de pena, que deje de lado los criterios referidos a la culpabilidad por el carácter y se acerque a la culpabilidad como reproche por el injusto, vid. Hörnle, Tatjana, Das antiquierte Schuldverständnis der traditionellen Strafzumessungsrechtsprechung und -lehre, JZ, N²2, 1999, p. 1087 [traducción al español de María Martin Lorenzo: La concepción anticuada de la culpabilidad en la jurisprudencia y doctrina tradicionales de la medición de la pena, Anuario de derecho penal y ciencias penales 2001, p. 401 ss.] 
Medina - Sobre la determinación de pena y el recurso de nulidad...

como reacción a las consecuencias indeseadas de la orientación a la prevención especial en la determinación de pena, extendida en diversos ordenamientos jurídicos ${ }^{26}$.

En el planteamiento de Hörnle, la teoría de la determinación de la pena es independiente de la teoría de la pena ${ }^{27}$. En su propuesta, esta autora indica la necesaria diferencia de planos entre la persecución de fines mediante el Derecho Penal, como institución, y la aplicación de una concreta pena, a esa diferencia subyace la necesaria separación entre la razón de existencia de una institución social y los principios que regulan su modo de operar en particular ${ }^{28}$.

Asimismo, la cuantía y clase de las sanciones tienen relaciones complejas en la interpretación de los tipos penales, en cuanto es posible que en el proceso de interpretación de los tipos penales, y sus variaciones, se tome en consideración el marco penal. Por ello, un aumento en el marco penal puede llevar aparejada una interpretación más restrictiva del tipo penal, cuestión que puede ser problemática en los casos en que la decisión del legislador precisamente pretende mantener los presupuestos de extensión de un tipo penal y agravar las consecuencias asociadas a su realización ${ }^{29}$.

El sistema chileno contemplado en la LRPA contiene elementos tanto vinculados a la determinación de la pena orientados al injusto, como elementos de carácter prevencionista. Este último se expresa particularmente en el literal f) del artículo 24 LRPA, referido a la idoneidad de la sanción para fortalecer el respeto del adolescente por los derechos y libertades de las personas y sus necesidades de desarrollo e integración social. No puede obviarse que éste es sólo uno de los seis criterios que el artículo 24 LRPA contempla y nada indica que debiese ser más relevante que los demás criterios.

Todo indica que los criterios de determinación de pena se orientan esencialmente a la precisión de los grados de disvalor de conducta y de resultado, de lo cual es fiel reflejo la enumeración de criterios contenidos en los literales a) a e) del artículo 24 LRPA, todos los cuales se relacionan con el grado de reproche por el hecho, con independencia de las consideraciones preventivas. Ello parece adecuado en un sistema de carácter proteccionista con el serio riesgo a caer en consideraciones paternalistas infundadas ${ }^{30}$, que podrían traducirse en la lógica, por

\footnotetext{
26 Feijoo, Bernardo, Individualización de la pena y teoría de la pena proporcional al hecho, In-Dret, $\mathrm{N}^{\mathrm{o}} 1,2007$, p. 5

27 Cfr. Hörnle, Tatjana, Tatproportionale Strafzumessung, p. 125 ss.

28 Hörnle, Tatjana, Tatproportionale Strafzumessung, p. 126.

29 Vid. Schroth, Ulrich, Hermeneutik, Norminterpretation und richterliche Normanwendung, en: Kaufmann/Hassemer/Neumann (Eds.) Einführung in Rechtsphilosophie und Rechtstheorie der Gegenwart, $7^{a}$ ed., C.F. Müller, Heidelberg, 2004, p. 291 s.

30 Es una cuestión obvia que las distintas capacidades de los menores justifican un ámbito de intervención coactiva que puede ser calificada de paternalismo. Ello no es problemático en la medida que se comprenda que esas medidas deben estar orientadas a posibilitar el desarrollo de la
} 
cierto perversa, de la privación de libertad total como mecanismo de protección de los intereses del menor.

\section{ii. El sistema legal general, en especial el contenido del artículo 69 y la valoración de las circunstancias modificatorias}

Tal como se ha indicado, el sistema chileno de determinación de pena establece reglas generales referidas al establecimiento del marco de la pena en el cual el juez debe fijar la sanción concreta. El proceso de determinación del marco penal aplicable incluye las fases de determinación del tipo penal aplicable, el establecimiento de su grado de ejecución y del grado de participación. Acto seguido, ha de procederse a la verificación de la concurrencia de circunstancias modificatorias de la responsabilidad penal, sean éstas de efecto especial o de efecto general, para después dar curso a las reglas que determinan el efecto de las circunstancias modificatorias. Entre esas reglas, las que deciden sobre la efectiva aplicación de una circunstancia, como los artículos 63 y 64 del Código Penal, y aquellas que regulan su concurrencia, artículos 65 y siguientes del mismo cuerpo legal.

En este último paso, aparece ya el fenómeno descrito como arbitrariedad judicial. En efecto, las reglas sobre efectos de las circunstancias modificatorias contemplan en diversos casos la posibilidad de aumentar o disminuir el marco penal aplicable a un hecho concreto. Dado que en esos casos el aumento o disminución es facultativo ${ }^{31}$, y la magnitud de la disminución es variable, pudiendo llegar a ser de hasta tres grados, se ha discutido asimismo la posibilidad de impugnar las resoluciones judiciales en razón de la aplicación de esas facultades.

Sin embargo, el proceso de determinación de la pena no concluye con el establecimiento de un grado o grados determinados en los cuales ha de enmarcarse la sanción a imponer, sino que nuestra legislación penal contempla una fase final de determinación de la pena, en la cual ha de establecerse la magnitud concreta de la pena. Así, el artículo 69 del Código Penal dispone que "dentro de los límites de cada grado el tribunal determinará la cuantía de la pena en atención al número y entidad de las circunstancias atenuantes y agravantes y a la mayor o menor extensión del mal producido por el delito".

Es innegable que la importancia de esta norma no se condice con la aplicación que ella suele encontrar en la práctica, pues nuestros tribunales suelen aplicar enfrentados al supuesto de la disposición la respectiva pena en su grado

autonomía del menor. Sobre esto vid. González. Contró, Mónica, Paternalismo jurídico y derechos del niño, Isonomía, $\mathrm{N}^{\circ} 25,2006$, p. 127.

31 Sobre la discusión acerca del carácter facultativo u obligatorio de los aumentos o rebajas en virtud de esta circunstancia vid.Rudnick Viz̨arra, Carolina, La compensación racional de circunstancias modificatorias en la determinación de la pena, p. 12 ss. 
Medina - Sobre la determinación de pena y el recurso de nulidad...

mínimo ${ }^{32}$. Sin embargo, el análisis de esos criterios puede dar una orientación a efecto de establecer posteriormente con mayor precisión, en qué forma han de ser aplicados los criterios que sobre el punto consagra el artículo 24 de la LRPA.

Dos son los criterios que el artículo 69 del Código Penal señala: (i) las circunstancias atenuantes y agravantes y (ii) la extensión del mal causado por el delito. Estos criterios deberían ser necesariamente considerados al momento de establecer cuál es el monto de la pena. Sobre el contenido de esos criterios nada se adelanta en esta sección, pues ambos están también indicados como factores a considerar por el artículo 24 LRPA. Será al referirse en particular a todos los criterios de esa disposición que se hará mención respecto al contenido de ambos elementos.

\section{Las particularidades de la determinación de penas en materia de responsabilidad penal juvenil}

\section{i. El sistema de sanciones en la Ley $\mathbf{2 0 . 0 8 4}$}

El sistema de sanciones de la LRPA presenta entre sus características esenciales, su dependencia del sistema de penas respecto del establecido en el Código Penal, según consagra el artículo 21 de la ley, el cual indica que para los efectos de la LRPA el tribunal debe aplicar la pena, partiendo de la inferior en un grado a la señalada por la ley para el delito correspondiente, cuando es cometido por un adulto. En ese contexto, las reglas de determinación de pena cumplen dos funciones: (i) reglas que permiten la determinación de un marco sancionatorio aplicable y (ii) reglas que permiten, en ese marco, el establecimiento de la naturaleza y entidad concreta de la sanción.

En ese sentido, la LRPA excluye expresamente la aplicación del artículo 69 del Código Penal, norma que establece el régimen general para, una vez determinado el marco dentro del cual ha de decidirse la entidad de la sanción, se establezca cuál es la pena concreta. Sin embargo, la normativa puede resultar confusa en cuanto a la aplicación del artículo 24, dado que expresa mención a los criterios de esa norma se encuentran sólo en el artículo $9^{\circ}$ de la LRPA, lo que sin embargo se explica por la suma de criterios adicionales a los del artículo 24 en el caso de la pena de multa, que consideran la capacidad económica del infractor y la persona que lo tuviere a su cuidado.

En consecuencia, no puede ponerse en duda que el artículo 24 LRPA cumple en el caso del régimen penal de los adolescentes, la misma función que el artículo 69 del Código Penal cumple en el régimen general, esto es, proveer de criterios que permiten fijar la magnitud de la sanción dentro de un marco

32 Matus/Van Weezel en: Texto y Comentario del Código Penal chileno, T. I, Editorial Jurídica de Chile, 2002, p. 374. 
REJ - Revista de Estudios de la Justicia - No 11 - Año 2009

predeterminado según las reglas legales. Junto a ello, la función del artículo 24 es proveer también de los criterios que orientan en la adopción de la clase de sanción adecuada.

\section{ii. La determinación de penas en el artículo 24}

Sin perjuicio de la aplicabilidad de criterios generales aquí expuestos sobre la determinación de la pena y su validez en el marco de los efectos de las circunstancias modificatorias en las normas que regulan sus efectos, este trabajo se centra en el artículo 24 LRPA y su aplicación. Esa disposición establece:

"Criterios de determinación de la pena. Para determinar la naturaleza de las sanciones, dentro de los márgenes antes establecidos, el tribunal deberá atender, dejando constancia de ello en su fallo, a los siguientes criterios:

a) La gravedad del ilicito de que se trate;

b) La calidad en que el adolescente participó en el hecho y el grado de ejecución de la infracción;

c) La concurrencia de circunstancias atenuantes o agravantes de la responsabilidad criminal;

d) La edad del adolescente infractor;

e) La extensión del mal causado con la ejecución del delito, y

f) La idoneidad de la sanción para fortalecer el respeto del adolescente por los derechos y libertades de las personas y sus necesidades de desarrollo e integración social."

Como se ha señalado, la norma precedentemente transcrita cumple dos funciones en el marco de la LRPA: (i) orienta la elección de una clase de sanción determinada; y (ii) entrega los criterios a considerar en la fijación de la magnitud final de la sanción.

Sobre las diversas teorías de la determinación de pena que se han revisado aquí con anterioridad, se descartan por sus inconvenientes ya señalados las teorías del ámbito de juego, y su consagración de la discrecionalidad, así como la teoría de la pena puntual, por su impracticabilidad. La teoría del valor relativo encuentra en Alemania esencialmente problemas de texto legal ${ }^{33}$, mismos que se presentan entre nosotros con otra connotación, pues aquí se enumeran los criterios de determinación de pena, la mayoría de los cuales dice relación con el disvalor del hecho conforme a la culpabilidad.

Por ello, una separación en un primer momento de determinación vinculado a la culpabilidad por el hecho y uno posterior referido a cuestiones preventivas no tiene fundamento legal entre nosotros. Más bien los dos

33 Lo que no sucede en España, de ahí que Feijoo sustente su plausibilidad, cfr. Feijoo, Bernardo, Individualización de la pena y teoría de la pena proporcional al hecho, In-Dret, N 1, 2007, p. 11. 
Medina - Sobre la determinación de pena y el recurso de nulidad...

momentos, referido a la determinación pre y post consideración de lo dispuesto en el artículo 24 LRPA se refieren siempre a cuestiones acerca del disvalor asociados a la culpabilidad por el hecho, en un primero paso de forma general, para después especificarlo según las características concretas del hecho.

Sobre esta doble función se ha vertido la crítica del riesgo de vulneración del principio ne bis in idem, por cuanto algunos de los factores enumerados en la disposición han sido de alguna forma ya considerados en las fases previas de la determinación de pena ${ }^{34}$.

La objeción puede ser considerada eventualmente como fundada, en la medida en que se trate de criterios ya valorados para el establecimiento del marco penal que no sean susceptibles, en modo alguno, de una diferenciación en la expresión del fenómeno criminal. En efecto, y esa es tarea del análisis de los criterios en particular.

Con relación a las diversas teorías sobre la determinación de la pena, no parece adecuado cerrarse a una sola, habida consideración de los diversos criterios que el mismo artículo 24 LRPA contiene. En todo caso, la opción preferente es aquella referida por criterios que den cuenta de la magnitud del injusto realizado, cuando ellos sean aplicables. Sobre este punto se volverá antes de tratar los criterios en particular.

\section{a) El catálogo de sanciones en la LRPA}

Entre las características del sistema de sanciones de la LRPA se encuentra el contemplar no sólo penas diferenciadas respecto de los adultos, sino también el establecimiento de modalidades diversas de afectación de la libertad ambulatoria u otra clase de afectaciones de derechos.

Así, el artículo $6^{\circ}$ de la LRPA enumera el catálogo de sanciones: a) internación en régimen cerrado con programa de reinserción social; b) internación en régimen semicerrado con programa de reinserción social; c) libertad asistida especial; d) libertad asistida; e) prestación de servicios en beneficio de la comunidad; f) reparación del daño causado; multa y h) amonestación. Como penas accesorias se contemplan tanto la prohibición de conducir vehículos motorizados, como el tratamiento forzado de rehabilitación por adicción a las drogas y el alcohol del artículo $7^{\circ}$ LRPA.

Es posible observar que el catálogo de penas establecido es muy diverso y debiese permitir al juez responder de modo proporcionado y eficiente a las

34 En ese sentido Horvitz, Lennon, María Inés, Determinación de las sanciones en la ley de responsabilidad penal juvenil y procedimiento aplicable, p. 24; Cillero, Miguel, Consideraciones para la aplicación del criterio de idoneidad en la determinación de las sanciones en Derecho Penal de Adolescentes Chileno, p. 31. 
distintas expresiones que pueden presentar los ilícitos cometidos. Es por ello que de acuerdo al artículo 23, existen diversos supuestos en los cuales la naturaleza de la sanción aplicable puede ser diversa, diversidad que por cierto implica importantísimas consecuencias para el condenado.

Así por ejemplo, en caso que la pena asignada a un ilícito, una vez consulta la penalidad general establecida para el hecho y considerada la regla de cálculo modificado de la LRPA del artículo 21, resulte ser una superior a 3 años y un día e inferior a 5 años, el juez posee la facultad de aplicar tanto un régimen cerrado o uno semicerrado de internación o libertad asistida especial. Es evidente el enorme margen de individualización de la pena que corresponde resolver judicialmente, de forma que debe existir un doble control que indique tanto la elección de uno u otro tipo de sanción, así como la extensión de ésta. La clase de sanción sólo indica uno de los aspectos de la condena a cumplir, pero no puede olvidarse que es considerablemente distinta una pena de régimen semicerrado de 3 años y un día frente a una de igual naturaleza, pero de una extensión de 5 años.

En todo caso, no debe olvidarse que los criterios de determinación legal e individualización judicial de la sanción están sometidos a controles adicionales del legislador, que pueden ocasionar la alteración del resultado que corresponde de acuerdo a la aplicación de las reglas ya referidas. Esas reglas corresponden a:

(i) los límites máximos de la sanción penal indicados en el artículo 18 LRPA que señala el máximo de la extensión de la sanción de régimen cerrado y semicerrado en virtud de la edad del sancionado, disposición que en virtud de los dispuesto en el artículo 22 LRPA tiene efecto directo sobre los marcos establecidos de acuerdo a las reglas preaplicación del artículo 24 LRPA, con lo que limitan la clase de sanciones aplicables a adolescentes de 14 y 15 años, quedando excluida la procedencia a su respecto del artículo $23 \mathrm{~N}^{\circ} 1 \mathrm{LRPA}$;

(ii) las restricciones del artículo 11 respecto de los servicios en beneficio de la comunidad;

(iii) el límite máximo de tres años para los casos de libertad asistida, tanto simple como especial, contemplado respectivamente en los artículos 13 y 14 de la LRPA.

Cabe agregar que una limitación similar se prevé para la sanción accesoria de prohibición de conducir vehículos motorizados, la cual no depende de la entidad de la pena sino que se sujeta al lapso restante para alcanzar los veinte años de edad por parte del condenado.

Finalmente, sin establecer un límite temporal concreto, las últimas pautas se presentan en el artículo 26 de la LRPA que se refiere expresamente a los límites de la imposición de sanciones privativas de libertad entregando tanto un criterio orientador referido al carácter de medida extrema de la privación de libertad, sin distinción de si ésta es total o parcial, y una regla extraordinaria de restricción de la 
Medina - Sobre la determinación de pena y el recurso de nulidad...

procedencia de privación de libertad para el infractor, que impide la aplicación cuando existen partícipes adultos y menores sancionados por el mismo hecho, y no se condena a una privativa de libertad al adulto.

La extensión de esta regla no es clara, pero dado el carácter extraordinario de la privación de libertad para menores parece ser irrelevante que al adulto se le sancione por un grado menor de participación en el hecho y al menor como autor, la regla del artículo 26 LRPA sería preferente y excluiría de todos modos la aplicación de una pena privativa de libertad, bastando acreditar la identidad del hecho atribuido a los distintos partícipes.

Como se refleja en las disposiciones anteriores, son múltiples los factores que han de tenerse en consideración a fin de establecer la pena en el caso concreto, pero es relevante a lo menos destacar desde ya, que las reglas antes mencionadas sobre límites de la pena concreta aplicable, no pueden ser, por regla general, consideradas antes de evaluar la clase de sanción aplicable, y su entidad, sino sólo una vez determinada la pena, como criterios de corrección ex - post frente a la sanción determinada. Por ello, su invocación y aplicación en la sentencia debe efectuarse siempre a continuación de las reglas generales y de la consideración de los criterios especiales del artículo 24 LRPA, salvo que expresamente se disponga algo distinto, como sucede con la regla del artículo 22 LRPA que ordena aplicar los criterios máximos de sanción contemplados en el artículo 18 LRPA, ya en el momento posterior a la determinación del marco general de extensión de la sanción, que corresponde según dispone el artículo 21 LRPA.

\section{b) El deber de expresión de los criterios en la sentencia}

Junto a lo anterior, es destacable en la norma citada que establece el deber del tribunal de atender a los criterios "dejando constancia de ello en su fallo". Ese deber de dejar constancia debe comprenderse como un especial llamado de atención al órgano judicial en cuanto a dar razón de la aplicación de los criterios en la determinación de pena. Ello no implica que a contrario sensu en materia penal general ese deber no exista. Sin embargo, dado que la norma lo contempla expresamente en la LRPA, el deber se vuelve especialmente exigible y despeja toda duda sobre el hecho que, en la fundamentación de la sentencia, la parte referida a la fundamentación del fallo debe hacer expresa consideración a los criterios.

Así, la norma del artículo 24 LRPA no sólo constituye una directiva de orientación para el juez al momento de optar por una clase de sanción determinada y fijar su extensión, sino también cumple una función de garantía y control de racionalidad de la decisión judicial sobre la pena aplicable ${ }^{35}$.

Esta función dice especial relación con la posibilidad de revisión del fallo en virtud de un recurso de derecho estricto como el de nulidad. Cuestión aparte es

\footnotetext{
35 Vid. Ziffer, Patricia, Lineamientos de la determinación de la pena, p. 96 ss.
} 
la determinación de la extensión del deber de referencia de la sentencia a los criterios establecidos en el artículo 24 LRPA. Ese deber puede ir desde la sola mención genérica de los criterios considerados para la elección de la sanción y la determinación de su extensión hasta la obligación de mencionar cada uno de ellos, sea que se haya considerado o no para efectos de determinación de la pena, debiendo pronunciarse en cada caso sobre si un determinado criterio ha sido o no utilizado, indicando en los casos en que se ha prescindido de alguno la razón de ello y en los demás casos señalando cómo se ha valorado el criterio para arribar a la pena establecida.

La última alternativa significa una evidente carga para el juez que a primera vista pareciese ser excesiva. Ello sólo es así dado que la habitual práctica decisoria en la materia no contempla esa modalidad de confección de la parte de la sentencia, que se refiere a la determinación de la pena, con tal intensidad. Sin perjuicio de ello, debe considerarse cuál es la forma en la que el sistema procesal se estructura y las instancias procesales que al respecto se contemplan.

En tal sentido, el artículo 40 LRPA establece que la audiencia de determinación de pena del artículo 343 del Código Procesal Penal se realizará de forma obligatoria en todos los casos de sentencia condenatoria. Con ello se despeja toda duda sobre el momento de discusión sobre la aplicación de los criterios y reglas relevantes para la determinación de la sanción. Es en esa oportunidad que los intervinientes tienen la posibilidad, y deber, de esgrimir todos los argumentos conducentes a individualizar la pena aplicable.

Puesto que el sistema procesal se estructura como adversarial con órgano persecutor separado de la labor jurisdiccional y mecanismo de defensa obligatoria, el deber del juez en cuanto al pronunciamiento sobre los criterios de determinación de pena se debiese extender, a lo menos, a las alegaciones de las partes, indicando si éstas son acogidas o no, y el por qué de ello, así como la forma en que son aplicadas en caso de acogerse.

Con lo anterior se satisface a lo menos formalmente, en términos de estructura del debate, el deber de dejar constancia sobre la aplicación de los criterios. Junto a ello, puede que ese deber no se haya cumplido materialmente, es necesario establecer cuál es el margen de razonamiento que el tribunal tiene respecto de esos criterios, es decir, determinar el contenido de ellos, para saber cuándo no se los ha tratado de manera adecuada.

\section{iii. Los criterios del artículo 24}

Como se indicó más arriba, la determinación de la pena aplicable está sujeta a criterios de racionalidad legalmente definidos que vinculan al juez al momento de elegir la sanción aplicable así como la magnitud de la misma. Aquí se trata de decidir la aplicación de los criterios y su incidencia en la elección de la sanción y la extensión de la misma. En ese sentido, es una cuestión sobre 
Medina - Sobre la determinación de pena y el recurso de nulidad...

aplicación de normas y no de ponderación de principios. No se trata de optimizar la aplicación de los criterios en la determinación de la pena, sino de analizar su concurrencia y efecto en el caso concreto ${ }^{36}$.

\section{a) La infracción al ne bis in idem}

La primera cuestión a dilucidar es si la consideración de los criterios, como afirma Horvitr, implica necesariamente una vulneración del principio ne bis in idem, así considerado, ese principio cumple el rol de una regla de exclusión de una circunstancia: si ella fue previamente considerada, no lo puede volver a ser. Dicho principio recogido, a lo menos indirectamente, en el inciso primero del artículo 63 del Código Penal, el cual indica que no producen el efecto de aumentar la pena las circunstancias agravantes que por si mismas constituyen un delito especialmente penado por la ley, o que ésta haya expresado al describirlo y penarlo. Tampoco lo producen aquellas circunstancias agravantes de tal manera inherentes al delito que sin la concurrencia de ellas no puede cometerse. En su formulación más amplia, ese principio prohíbe la duplicidad de sanciones a una misma persona por los mismos hechos.

Este principio extiende sus alcances en diversos ámbitos. Así, supuestos clásicos de posible conflicto con el ne bis in idem constituyen la aplicación conjunta de sanciones penales y administrativas, las medidas de seguridad y sanciones penales, la doble valoración de circunstancias modificatorias de la responsabilidad penal y su expresión en el principio de inherencia, entre otras ${ }^{37}$.

También es discutido el rango que el principio del ne bis in idem posee, pues no existe una consagración constitucional expresa del mismo. Sin perjuicio de ello, puede considerarse que tal principio es en parte reflejo del principio de legalidad y en parte también del principio de proporcionalidad ${ }^{38}$.

La pregunta aquí se presenta con relación a los criterios que el legislador tiene presente al momento de fijar los marcos abstractos de penalidad para los delitos y la concurrencia de esos criterios, de acuerdo al artículo 24 LRPA, al momento de determinar la sanción concreta. Así, la afirmación del conflicto por parte de Horvitz se estructura sobre un presupuesto cuestionable: las posibles valoraciones del injusto y sus diversas manifestaciones se encuentran ya recogidas en la formulación de los tipos penales y la aplicación de las reglas generales que los $\operatorname{afectan}^{39}$. Esas reglas se expresan como cuestiones particulares de la teoría del

\footnotetext{
36 Otra opinión Cillero, Miguel, Consideraciones para la aplicación del criterio de idoneidad en la determinación de las sanciones en Derecho Penal de Adolescentes Chileno, p. 29.

37 Cfr. Garcias Planas, Gabriel, Consecuencias del principio "non bis in idem" en Derecho Penal, ADPCP, T. XLII, Fasc. I, 1989, p. 109 ss.

38 Boix Reig, Javier, La jurisprudencia constitucional sobre el principio non bin in idem, en: Agustín Jorge Barreiro (Ed.) Homenaje al Profesor Dr. Gonzalo Rodríguez Mourullo, Civitas, Navarra, 2005, p. 128 ss.

39 Horvitz Lennon, María Ines, Determinación de las sanciones en la ley de responsabilidad penal juvenil y procedimiento aplicable, p. 24 ss.
} 
delito, como la referida a la sanción de los casos de delito culposo o bien, por medio de reglas modificatorias que alteran la valoración del disvalor de injusto o de resultado.

Ello sería correcto en la medida que la descripción de los tipos penales y las reglas que permiten modificar las distintas expresiones del injusto abarcaran con detalle las distintas expresiones de las conductas ilícitas, por lo que el riesgo de vulneración del ne bis in idem existe ${ }^{40}$. Lo cierto es que los tipos penales, y las reglas complementarias, sólo expresan, y sólo eso pueden hacer, rangos en los cuales la sentencia puede ser expresada, pero la concretización está entregada al juez. Ello es evidente cuando se observa, particularmente en la LRPA, que fruto del resultado de la aplicación de las reglas generales sólo se obtiene un catálogo de posibles sanciones y topes máximos y mínimos en la extensión de éstas.

Lo cierto es que con independencia de la pre-valoración de ciertas cuestiones relativas al disvalor de injusto y al de resultado de un hecho criminal, aún es posible refinar más el análisis. Por ello los criterios del artículo 24 LRPA se refieren en muchos casos a cuestiones propias de la valoración de la conducta penal que ya han sido considerados, pero cuyo análisis puede ser refinado una vez que la subsunción de la conducta a un tipo legal ya se ha efectuado. Sobre cómo es posible esa operación, se indica en el análisis separado de cada uno de los criterios.

Por ello, no es relevante que se considere en más de una ocasión una misma categoría de relevancia para el injusto, sino que sea valorado un mismo hecho o circunstancia más de una vez. De ahí lo importante del deber de fundamentación de la sentencia en su parte considerativa, en especial la subsunción de los hechos probados bajo los supuestos legales correspondientes, sino que ello se vincula directamente con el deber de expresión de los criterios considerados para determinación de la pena.

Múltiples casos se presentan como problemáticos al momento de definir la infracción del ne bis in idem. Entre ellos se pueden considerar los tipos penales con múltiples alternativas de realización, como el homicidio calificado o las lesiones. En esos casos puede considerarse que satisfechos los presupuestos de realización del injusto típico, queda un espacio para considerar las modalidades alternativas de realización como elementos de determinación de la pena concreta ${ }^{41}$. Asimismo, es aún posible al interior de una modalidad, como la comisión por medio de arma, diferencias en disfavor del condenado acerca de la clase de arma que se trate ${ }^{42}$. Estos ejemplos muestran que la infracción del ne bis in idem es una cuestión límite en muchos aspectos de la determinación de pena, pero no un principio que

\footnotetext{
40 Vid. Demetrio Crespo, Eduardo, Prevención general e individualización judicial de la pena, p. 290 s. 41 Vid. Teuhne, \46, Rdn. 266. en: Jähnke, Burkhard/Laufhütte, Heinrich Wilhelm/Odersky, Walter (Eds.), Strafgesetzbuch, Leipziger Kommentar, Großkommentar, 12ª ed., De Guyter Recht, Berlin, 2005, citado en adelante LK/autor

42 Ejemplo utilizado en NK/Streng, \46, Rdn. 130.
} 
Medina - Sobre la determinación de pena y el recurso de nulidad...

necesariamente se infrinja. Sobre esto se volverá en la revisión de los criterios del artículo 24 LRPA.

\section{b) La elección de la clase de sanción}

Una cuestión previa a la que referirse trata sobre la valoración diferenciada de las sanciones que pueden imponerse. Aquí se trata de establecer si existe un orden absoluto en la entidad de las sanciones de modo tal que se permite afirmar que la privación de libertad en todo caso constituye la modalidad más grave de sanción, mientras que la amonestación por definición es la más baja, mientras que las sanciones están ordenadas por gravedad, en forma decreciente, en el modo que aparecen en la tabla demostrativa del artículo 23.

Dado que nuestro sistema penal, incluida la LRPA, no contempla el sistema de días-multa, no es factible un simple cálculo comparativo entre penas privativas de libertad y la de multa. En el caso de la LRPA ello es especialmente decisivo, pues casos como el tramo de penas de 3 años y un día a 5 años contemplan un catálogo de sanciones muy diversas. En efecto, previo a la determinación de la extensión temporal de la sanción resulta más decisivo la disyuntiva entre una privación total de libertad (régimen cerrado), una parcial (régimen semicerrado) y una mera restricción de la libertad (libertad asistida especial).

Claramente esos constituyen tres clases de sanciones de entidades radicalmente distintas, porque lo que el razonamiento sobre determinación de pena deberá explicar en cada caso, qué motivos llevan a preferir una sanción sobre la otra, considerando que mientras más intensa es la afectación de la libertad, de mayor entidad deben ser los antecedentes que justifiquen la elección de la sanción. Todo lo anterior sin perjuicio que en los casos más graves, esto es, aquellos que se refieran al numeral primero del artículo 23, la LRPA no prevé distintas sanciones, sino que las argumentaciones sobre determinación de pena sólo se refieren a la duración de ésta.

\section{c) El análisis de los criterios}

Tal como se indicó anteriormente, la determinación de pena depende en buena parte de cuál es el contenido que se da a los criterios que la determinan. Por ello, a continuación se hará una breve referencia a cada uno de los criterios mencionados en el artículo 24 LRPA indicando cómo pueden incidir éstos en la elección de la sanción y la fijación de la extensión. 


\section{c.1 La gravedad del ilícito de que se trate}

El primero de los criterios que enumera el artículo 24 se refiere a la gravedad del ilícito por el cual se sanciona. Aquí observa Horvitz ${ }^{43}$ un primer caso de conflicto con la máxima del ne bis in idem. Esa observación la fundamenta la autora, en el hecho que la gravedad del delito constituye ya uno de los elementos claves de la valoración del legislador a efectos de asignar pena a los distintos delitos. Así, afirma que "... todos aquellos aspectos, elementos o circunstancias que fundan el ilícito, esto es, que han sido tomados en consideración por el legislador al configurar el tipo penal y la extensión de la pena, no pueden ser valorados nuevamente- en un sentido desfavorable al reo_ para seleccionar, esta vez, la clase o naturaleza de la sanción aplicable" ${ }^{94}$.

Sin embargo, esta apreciación puede ser algo apresurada, pues ella parte del supuesto que en la descripción y valoración que el legislador efectúa al establecer un ilícito penal los elementos contenidos son de tal naturaleza, que no permiten diferenciar grados de intensidad en la vulneración de la norma. Tal concepción del injusto penal deja de lado la multiplicidad de conductas, susceptibles de distinta apreciación, que puede dar lugar a la infracción de una misma norma penal.

Para ello es de utilidad la orientación a la teoría del delito ${ }^{45}$, y en particular a la clásica distinción entre disvalor de conducta y disvalor de resultado ${ }^{46}$. En cuanto al disvalor de la conducta, puede resultar apropiado el ejemplo del robo con violencia. El elemento violencia es el que justifica tratar al robo con violencia como una forma calificada de coacción ${ }^{47}$, sin embargo, las manifestaciones de la violencia pueden ser diversas, lo que justifica una penalidad diferenciada ${ }^{48}$, sin que por ello se vulnere el ne bis in idem.

En ese sentido, los criterios propuestos, a modo ejemplar, por Silva Sánche ${ }^{49}$ pueden ilustrar cuáles son los elementos que pueden dar lugar a una distinta apreciación y, por ende, a una distinta pena concreta. Así, el injusto subjetivo de una norma penal puede ser satisfecho con diversos grados de reproche, escala en la cual puede concurrir tanto el dolo eventual como el dolo directo, sea de primer o segundo grado.

43 Horvitz Lennon, Maria Inés, Determinación de las sanciones en la ley de responsabilidad penal juvenil y procedimiento aplicable, p. 25.

44 Horvitz Lennon, María Ines, Determinación de las sanciones en la ley de responsabilidad penal juvenil y procedimiento aplicable Determinación de las sanciones, p. 25.

45 Así Hörnle, Tatjana, Tatproportionale Strafzumessung, p. 144.

46 Roxin, Claus, Strafrecht, AT I, \10, Rdn. 88 ss.

47 Vid. Bascuñan Rodríguez, Antonio, El robo como coacción, Revista de Estudios de la Justicia, N 1 , 2002, p. 55 ss.

48 Ziffer, Patricia, Lineamientos de la determinación de la pena, p. 107. Así en el razonamiento del fallo sobre recurso de nulidad de la Corte de Apelaciones de Temuco, de fecha 20 de julio de 2007, Rol 709-2007, Considerando $7^{\circ}$.

49 Silva Sánchez, Jesús M. La teoría de la determinación de la pena como sistema (dogmático): un primer esbozo, In-Dret, 2007, p. 11 ss. 
Medina - Sobre la determinación de pena y el recurso de nulidad...

Esta distinta forma de vulneración de una norma penal puede, por ende, dar lugar a juicios de reproche diferenciados que no encuentra expresión sino al momento de la fijación de una concreta magnitud de pena, precisamente por aplicación del criterio de la gravedad del ilícito. No reconocer ese momento del reproche penal sería equivalente a obviar las diferencias propias de la comisión de un ilícito con distintos grados de intensidad en el aspecto subjetivo del tipo, lo cual es en una teoría orientada a sopesar la real gravedad del injusto, algo esencial. Asimismo, ello no constituye afectación alguna del ne bis in idem, aún cuando la sola invocación de una misma circunstancia fuese suficiente para plantear un conflicto de aplicación en esos términos.

También pueden considerarse como factores que inciden en la determinación de pena, la aplicación de las soluciones de concurso aparente de leyes, según las cuales el desvalor de ciertas conductas queda subsumido en el de la conducta principal, con lo cual ello no tiene un efecto en la fijación del marco legal de pena, pero sí puede ser evaluado en la determinación de la clase de sanción y la cuantía de la misma.

Como estas reflexiones ejemplares demuestran, es posible realizar una especificación del disvalor de injusto, sin infringir el principio del ne bis in idem, en múltiples casos. La enumeración de todos ellos es una tarea compleja que excede con creces este trabajo y cuyo desarrollo es materia de la labor jurisprudencial y dogmática.

\section{c.2 La calidad en que el adolescente participó en el hecho y el grado de ejecución de la infracción}

Este elemento se suele considerar también como de aquellos a los que puede objetarse una infracción al ne bis in idem. Dado que el grado de participación y el grado de ejecución están contemplados como reglas que determinan el marco, por lo que no podrían ser nuevamente valoradas. Si bien ello es principio correcto, debe tenerse en consideración que las reglas sobre autoría y grado de ejecución no necesariamente determinan de manera exhaustiva el grado de disvalor del injusto ni el reproche por la contribución particular en la realización del hecho.

Así por ejemplo, dentro de los diversos comportamientos que acorde al artículo 15 del Código Penal pueden ser calificados de autoría, se presenta un espectro fenomenológico de gran amplitud. Que la inducción sea una forma de participación calificada especialmente como autoría ${ }^{50}$, de acuerdo al artículo $15 \mathrm{~N}^{\circ}$ 2 del Código Penal, en nada impide que se le pueda considerar para efectos de determinación de pena, como una forma de participación que merezca menos reproche.

\footnotetext{
50 Así Yañez, Sergio, Problemas básicos de la autoría y la participación en el Código Penal chileno, RCP, T. XXXIV, N 1, 1965, p. 62. [republicado en Polit. Crim. N 1, 2006, CH3]
} 
En el mismo sentido, desde una lectura no sólo formal del artículo 15 del Código Penal, se pueden establecer distintos grados de reproche respecto al dominio del hecho típico, que pueden reflejarse en el momento del establecimiento de una pena concreta. Consideraciones similares se pueden efectuar respecto del grado de ejecución, en cuanto ésta se aplica a una cadena de sucesos que no en todos los casos sólo da cuenta de tres momentos relevantes, sino de diversos sucesos que pueden ser encasillados en los tres momentos legislativamente considerados: tentativa, tentativa acabada y consumación. La posibilidad de distinguir múltiples sucesos, algunos de ellos constituyendo parte de un mismo estadio de la ejecución también es un factor que puede ser evaluado a efectos de la determinación de pena.

\section{c.3 La concurrencia de circunstancias atenuantes o agravantes de la responsabilidad criminal}

Este criterio se encuentra presenta en la regulación general de la determinación de pena de acuerdo al artículo 69 del Código Penal. En efecto, puede también aquí presentarse un conflicto con la idea del ne bis in idem. Sobre ello se pronuncia ya $V$ an $W$ eezel, quién desde una concepción orientada a fines de la determinación de la pena en el contexto del artículo 69 del Código Penal, propone algunos criterios para salvar una eventual colisión con el mencionado principio $^{51}$. Así, afirma que no existiría tal conflicto si previamente las circunstancias sean en esta última fase valoradas de modo global y con orientaciones preventivas.

No parece posible que la mera valoración global sea una salida a la infracción del ne bis in idem, puesto que no es lo relevante la consideración individual o conjunta de las circunstancias, sino el hecho que la consideración de una circunstancia ya haya tenido un efecto concreto en la determinación de marco de la pena.

La cuestión también podría tener otra respuesta, en la medida que la concurrencia de los supuestos fácticos de las circunstancias modificatorias pueden ser también graduados. Esto es especialmente notorio en el caso de la norma que permite calificar a una circunstancia atenuante como muy calificada (artículo 68 bis $\mathrm{CP}$ ), otorgándole efectos especiales en ese caso. Se demuestra así, que la verificación de la concurrencia de circunstancias modificatorias no es una cuestión binaria, sino que el juez tiene la facultad de, considerándola concurrente y sin llegar a catalogarla como muy calificada, tenga una entidad comparativa que justifique su influencia a nivel de determinación final de pena.

A lo anterior cabe hacer presente, que tal argumento sólo podría operar en la medida que la "compensación racional" de circunstancias modificatorias se

51 Van Weezel, Alex, Determinación de la pena exacta: El artículo 69 del Código Penal, Ius et Praxis, Año 7, N² 2, p. 406 s. 
Medina - Sobre la determinación de pena y el recurso de nulidad...

siguiese aplicando de forma matemática, esto es, las atenuantes y agravantes se anulan recíprocamente, sin consideración a la entidad ${ }^{52}$. En caso de corregirse este defecto en el procedimiento de determinación de pena, sólo subsistiría como alternativa válida la consideración global de circunstancias modificatorias como criterio relevante a efectos de la determinación en el marco del artículo 24 LRPA, o igualmente del artículo 69 del Código Penal.

\section{c.4 La edad del adolescente infractor}

Uno de los criterios esenciales de determinación de pena de la LRPA es la edad del adolescente condenado, con base a lo cual se establece un máximo de duración de las penas temporales, de 5 años a menores de 16 años y de 10 años a menores entre esa edad y los 18 años.

Es evidente que el criterio de la edad da cuenta de un menor reproche de culpabilidad, en la medida en que el menor es menos susceptible de motivación normativa, según su edad decrece. La reiteración de este criterio ahora, para efectos de la determinación de la naturaleza y duración final de la sanción, permite hacer un examen aún más detallado de la edad. Así, puede resultar justificado diferenciar en la pena concreta que ha de imponerse en un caso a un menor de 14 años, frente a uno que se aproxima a cumplir el límite de los 16 años.

Este criterio refleja las sutilezas plausibles en el momento final de la determinación de pena, pues la individualización permite precisamente dar razón de los diferentes estadios de desarrollo de un sujeto, cuestión central en la responsabilidad penal adolescente. Huelga decir que una posible infracción del ne bis in idem en este caso, siendo posible, es del todo evitable.

\section{c.5 La extensión del mal causado con la ejecución del delito}

Aquí se encuentra el segundo criterio contemplado en el artículo 69 del Código Penal, como general para la concretización de la pena en nuestro ordenamiento jurídico penal. La idea de mal causado presupone la necesaria valoración del resultado ocasionado con la comisión del ilícito. En tal sentido, la idea de "mal" como resultado no puede entenderse en forma restringida. En consecuencia, este es un criterio no sólo aplicable a aquellas conductas en las cuales hay un resultado material verificable, ni tampoco sólo a aquellas figuras penales que puedan clasificarse bajo el concepto de delitos de resultado.

En general, cualquier norma penal que proteja legítimamente un bien jurídico está siempre estructurada acorde a la idea de una forma de afectación del bien jurídico tutelado. En ese orden de ideas y considerando al mal causado como un fenómeno de naturaleza normativa, es posible efectuar diversas

\footnotetext{
52 Rudnick Vizcarra, Carolina, La compensación racional de circunstancias modificatorias en la determinación de la pena, p. 39 ss.
} 
consideraciones respecto a la intensidad de la afectación del bien jurídico. A ello en nada obsta que el tipo penal concreto esté concebido como una forma de afectación distinta a la lesión del bien jurídico tutelado, pues también en los delitos de peligro es posible efectuar juicios acerca de la mayor o menor expresión de esa forma de afectación.

El principio del ne bis in idem puede jugar aquí un rol, en aquellas conductas en las cuales diversas alternativas punibles están estructuradas sobre la idea de la extensión del resultado, como sucede en el sistema de tipificación de las lesiones o en el de la estafa y sus figuras asociadas. Sin embargo, aún en esa clase de normas penales los marcos admiten graduabilidad al interior, lo que posibilita hacer diferenciaciones al momento imponer penas concretas.

Los casos que resultan problemáticos se vinculan con la doble valoración del resultado ya considerado en la norma de comportamiento y los casos de daños extratípicos. En el primer supuesto se trata de aquellos razonamientos judiciales que re-consideran el reprochable daño que la conducta delictiva significa, como es la muerte de una persona en caso de un homicidio, cuestión que puede invocarse aquí o en el literal a) del artículo 24 LRPA. Esto constituye sin duda una vulneración del ne bis in idem, pues la pena abstracta del delito ya considera la importancia relativa del bien jurídico vida en nuestro ordenamiento penal.

A esto se agrega la consideración de circunstancias extratípicas vinculadas con el daño a la familia de la víctima ${ }^{53}$. El argumento se refiere aquí a las consecuencias no expresamente previstas por la norma que pueden emplearse como criterios de determinación de la pena en un sentido amplio del "mal" causado. Ellas serían consecuencias negativas para bienes no penalmente protegibles, pues ellos dan lugar a la aplicación de reglas de concursos ${ }^{54}$. En cuanto a resultados extratípicos, es indudable que su utilización a efectos de la determinación de pena es problemática, pues no se funda el reproche penal en cuestiones previstas en el tipo penal, con lo que se afecta la función de garantía del principio de legalidad. Sin embargo, es práctica usual de la judicatura el considerar esta clase de circunstancias en la determinación de la sanción. En tal caso, a lo menos es exigible que tales circunstancias le sean al condenado reprochables en cuanto al conocimiento de estos factores extratípicos ${ }^{55}$.

53 En ese sentido la sentencia del 1er. TJOP de Santiago, de fecha 09 de enero de 2008, en causa RIT 93-2007, que fue recurrida de nulidad, la que fue rechazada por sentencia de la I. Corte de Apelaciones de Santiago, de fecha 20 de marzo de 2008, Rol 120-2008. La sentencia del TJOP indica en su considerando $19^{\circ}$ "... que el cese de la vida de una persona que forma parte de un grupo familiar, extiende el mal causado a sus seres queridos" por lo que considera los trastornos psicológicos de los familiares producto de la muerte de la víctima "... como una consecuencia del hecho ilícito".

${ }^{54}$ Así Silva Sánchez, Jesús M. La teoría de la determinación de la pena como sistema (dogmático): un primer esbozo, In-Dret, 2007, p. 12, N al P. 39.

${ }_{55}$ En ese sentido LK/Theune, \46, Rdn. 150. También se han considerado, en la jurisprudencia alemana, como factores extratípicos relevantes para la determinación de pena el monto del daño fiscal en el delito de soborno de funcionario de aduanas, el monto de los daños ocasionados 
Medina - Sobre la determinación de pena y el recurso de nulidad...

\section{c.6 La idoneidad de la sanción para fortalecer el respeto del adolescente por los derechos y libertades de las personas y sus necesidades de desarrollo e integración social}

El último de los criterios contemplados en el artículo 24 LRPA, es de aquellos que no cabe interpretar sino en clave de orientación a fines. En efecto, la propia LRPA se encarga de señalar en su artículo 20 las finalidades a las cuales se orientan las sanciones de la ley, esto es, intervención socioeducativa amplia orientada a la plena integración social. Esta finalidad puede entenderse como una forma de consagración de la prevención especial positiva como fin primordial de la ley. Ello no obsta, en modo alguno, a consideraciones retributivas en la determinación de pena, en cuanto también función de las sanciones es hacer efectiva la responsabilidad de los adolescentes infractores por los hechos delictivos que cometan, en tal sentido la orientación al hecho es tan obligatoria como la orientación a fines.

En todo caso, la cuestión de la procedencia orientada a fines debiese ser un criterio posterior a la consideración de aquellos criterios vinculados a la determinación del disvalor del injusto del hecho. En particular, el criterio ahora analizado hace referencia a un parámetro, el de idoneidad y los fines: fortalecer el respeto del adolescente por los derechos y libertades de las personas, que puede vincularse con la idea de prevención general positiva orientada a un grupo específico de destinatarios de las normas penales, y sus necesidades de desarrollo e integración social, con lo cual el baremo de la idoneidad se desvincula de componentes estrictamente relacionados con los fines del Derecho Penal o con la constatación de un particular disvalor de injusto.

El concepto de idoneidad implica una obvia asociación con este concepto como integrante del principio de proporcionalidad en sentido amplio ${ }^{56}$. Como es bien sabido, el principio de proporcionalidad puede entenderse integrado a la vez por distintos subprincipios: el de necesidad, el de idoneidad y el de proporcionalidad en sentido estricto. En ese contexto la idea de idoneidad se entiende como un criterio negativo vinculado a la idea de orden marco ${ }^{57}$ y que sólo prejuzga sobre la adecuación de una medida para la obtención de un determinado fin.

En sede judicial, ello correspondería a la idea que contando el sentenciador con la posibilidad de establecer distintas sanciones, de distinta duración, deberá

producto de una declaración falsa en un juicio, en caso de la adquisición de la tenencia de un auto mediante estafa, los daños materiales ocasionados al vehículo como consecuencia de un accidente culpable por parte del autor. Ibid. Rdn. 151.

56 Alexy, Robert, Theorie der Grundrechte, Suhrkamp, Baden-Baden, 1994, p. 103.

57 Vid. Lopera Mesa, Gloria-Patricia, El principio de proporcionalidad y los dilemas del constitucionalismo, Revista Española de Derecho Constitucional (Nueva Época), N 73, 2005, p. 393. 
excluir las alternativas que no satisfagan esos fines en el caso concreto, de lo cual deberá dar cuenta en la respectiva resolución. Esto es, deberá prescindir de aplicar una sanción cuando se estime que con ella no se conseguirá fortalecer el respeto por la libertad y derechos de las personas o no contribuirá a las necesidades de desarrollo e integración social del adolescente.

Especial relevancia debe otorgarse, a efectos de determinar las necesidades de desarrollo e integración social del sancionado, al concepto de interés superior del adolescente, consagrado en el artículo $3^{\circ}$ LRPA. Él representa una máxima general de interpretación que da especial relevancia al respeto de los derechos de los menores infractores. Problemático puede resultar aquí la lectura del interés superior del adolescente en clave paternalista ${ }^{58}$, pues la determinación de la medida más idónea respetando el interés superior del adolescente, si bien se efectúa por un tercero sobre el sujeto afecto a las medidas, ese tercero, el juez, debe hacerlo desde la perspectiva del menor y sus intereses individuales de desarrollo y desde la perspectiva de lo que el Estado o la sociedad pueden estimar como finalidades útiles para el desarrollo del menor. Esa concepción es irrenunciable como contrapartida del reconocimiento al menor de un ámbito de autonomía que le permite asumir responsabilidad por infracciones penales. Sin perjuicio de lo anterior, la formulación del criterio del literal f) del artículo 24 parece tener también consecuencias en la comprensión de la culpabilidad del menor y su déficit de sociabilidad, que ha de ser resuelto por la sanción.

Por último, cabe considerar la posible contradicción en ambos fines. Por una parte el fin de reafirmación del respeto por normas parece impulsar un efecto de prevención especial negativa en el adolescente, en cuanto a una interpretación de costes de la sanción como medida educativa. Por la otra, es evidente que a mayor grado de privación de libertad, mayor es la pérdida de socialización del adolescente. Contra eso no cabe esgrimir que el ambiente del adolescente es perjudicial para su desarrollo, pues ello no puede traducirse en la privación de libertad como solución. El coste de un ambiente favorable de vida para el adolescente debe ser del Estado, de modo tal que éste proporcione un ambiente de desarrollo en libertad, que a la vez pueda complementarse con una restricción de la libertad acorde a la culpabilidad por el hecho.

\section{El recurso de nulidad ante la determinación de penas en la Ley $\mathbf{N}^{\circ}$ 20.084}

El recurso de nulidad representa en nuestro sistema procesal penal el mecanismo por el cual se solicita al superior jerárquico de un tribunal que invalide el juicio oral o la sentencia, o solamente esta última, cuando en cualquier etapa del procedimiento o en el pronunciamiento de la sentencia se hubieren infringido sustancialmente derechos o garantías asegurados por la Constitución o por los

\footnotetext{
58 Vid. N. 29.
} 
Medina - Sobre la determinación de pena y el recurso de nulidad...

tratados internacionales ratificados por Chile que se encuentran vigentes o cuando, en el pronunciamiento de la sentencia, se hubiere hecho una errónea aplicación del derecho que hubiere influido en lo dispositivo del fallo.

Este recurso constituye la vía principal de impugnación de las sentencias definitivas dictadas en un procedimiento ordinario o simplificado, sin perjuicio que pueda considerarse que el recurso de apelación en el caso del procedimiento abreviado en caso alguno obsta para la revisión judicial de los criterios de aplicación sobre normas de determinación de pena.

\section{i. El recurso de nulidad y la violación de las reglas de determinación de pena en el Derecho Penal}

Revisados los criterios que inciden en la determinación judicial de la pena, cuestión distinta es ver si defectos en su aplicación o interpretación pueden constituir vicios de la sentencia, de tal carácter que admitan su revisión por vía de recursos de derecho estricto. En tal sentido se revisa a continuación brevemente cuáles posibles líneas de argumentación pueden presentarse. Para ello, en un primer paso se da cuenta de la praxis judicial histórica asociada al recurso de casación y su procedencia a efectos de atacar decisiones referidas a la determinación de pena. En seguida, se revisa cuál es el estatus que pueden poseer las decisiones sobre determinación de pena, de tal modo que puedan originar vicios atacables por vía del recurso de nulidad, conforme lo regula el Código Procesal Penal.

\section{a) La casación en materia penal y la jurisprudencia sobre infracción de las normas}

La revisión de las sentencias judiciales en cuanto a la aplicación de las normas que regulan la determinación de pena revelan esencialmente que las Cortes suelen comprender las reglas de determinación de pena como el ejercicio de una potestad discrecional que impide su revisión por vía de recursos de derecho estricto. Sin perjuicio de ello, tanto la doctrina como la jurisprudencia desde larga data han manifestado su disconformidad con cuestiones relacionadas a los juicios sobre determinación de pena y la fundamentación de las sentencias judiciales.

En efecto, señala ya Politoff que “... no parece convincente que la ley limite la motivación [de las sentencias] a la existencia y calificación de las circunstancias y no la extienda al efecto de las misma, ya que, despojadas de su función mitigatoria del reproche penal, no se advierte por qué el juez, es constreñido a explicar si existen o no tales atenuantes. Debe entenderse que la reflexión no se agota con el reconocimiento de que las atenuantes existen... Porque la motivación interesa en la medida que abarca los elementos que ejercieron influjo en la determinación de la pena. Como la ley exige siempre la ponderación de los datos que conducen a afirmar o negar la presencia de las atenuantes, babrá que concluir que reclama, implícitamente, una explicación razonada sobre el porqué en una caso dado, no obstante su concurrencia, ellas no 
influyeron en la elección de la pena." ${ }^{39}$. Aún cuando las palabras de Politoff se refiriesen a la cuestión sobre los efectos de las modificatorias, resulta indudable que sus argumentos son del todo válidos para el problema general de la determinación de pena y su revisión mediante recursos de derecho estricto, en este caso por vía de la casación en la forma con relación al deber de fundamentación de las sentencias judiciales.

Esa misma forma de argumentación se encuentra presente en otros fallos de tribunales superiores de nuestro país, que de cuando en cuando emiten dictámenes que invocan la necesidad de fundar en la sentencia la aplicación e interpretación de las reglas relativas a la determinación de pena. Así se ha afirmado " $3^{\circ}$ Que al exigir la ley que la sentencia contenga, junto con otros requisitos atinentes, "las razones legales o doctrinales que sirven para calificar el delito y sus circunstancias, tanto las agravantes como las atenuantes", persigue que todo fallo sea capaz de explicar por si mismo los motivos de becho y los razonamientos de derecho que, necesariamente, conducen a su conclusión, de modo que pueda llevar al ánimo de las partes y de la comunidad en general, el convencimiento de que es auténtica expresión de justicia" ${ }^{60}$.

Cuestiones similares sobre la necesidad de fundamentación se han planteado también no sólo en la expresión de los criterios sobre la procedencia y aplicación de circunstancias modificatorias, sino también respecto al ejercicio de facultades relativas a aumentos o rebajas de penas ${ }^{61}$, lo que no es sino otra manifestación de la idea de fundamentación respecto a la individualización de la pena aplicable. Todo lo anterior no obsta a que los tribunales superiores, de manera poco orgánica, han ejercido un control sobre la calificación de circunstancias modificatorias y sus efectos, cuestión que se puede ejemplificar con el control del artículo 68 bis del Código Penal y la procedencia de estimar una circunstancia atenuante como muy calificada ${ }^{62}$.

\section{b) El recurso de nulidad por infracción del artículo 24 de la Ley 20.084}

El recurso de nulidad representa la vía de impugnación de sentencias por causales de derecho estricto en nuestro sistema procesal penal. En ese contexto, y habiendo clarificado que la determinación de pena no es una cuestión que obedezca a criterios meramente fácticos o al ejercicio de una potestad incontrolable del sentenciador, cabe referirse a cuáles son los motivos sobre los cuales puede fundarse un recurso de nulidad en la materia. Por un orden lógico se analiza a continuación en primer lugar la falta de fundamentación y, acto seguido, la infracción a derecho.

\footnotetext{
59 Politoff, Sergio, RCP, tercera época, Mayo-Agosto 1968, p. 141.

60 Corte Suprema, 01 de junio de 1972, RCP, Tercera época, mayo-diciembre 1972, p. 166 ss.

61 Así Corte Suprema, 03 de mayo de 1968, RDJ, T.LXV, N 3, p. 83.

62 Sobre ello y con múltiples referencias a la jurisprudencia vid. Matus/Van Weežel en: Texto y Comentario del Código Penal chileno, p. 372 s.
} 
Medina - Sobre la determinación de pena y el recurso de nulidad...

\section{b.1 La falta de fundamentación como causal}

Como ya se ha indicado, el artículo 24 LRPA establece un deber explícito del sentenciador de referirse a los criterios que la disposición establece como determinantes al momento de elegir una sanción de las posibles y decidir sobre la duración de esa sanción. No es correcto afirmar que sin ese mandato expreso nos encontraríamos ante la ausencia de tal deber, puesto que el deber de dar razón sobre la imposición de una sanción no puede limitarse sólo al establecimiento del título de la incriminación. Esta causal ha suscitado intenso debate y reflexión en nuestro ordenamiento jurídico, pero ello vinculado esencialmente a la falta de valoración de la prueba ${ }^{63}$.

No obstante, el mandato del artículo 24 LRPA no puede considerarse como satisfecho con una invocación formal de los criterios ahí mencionados. Esto es, la sola mención consignada como "atendido la extensión del daño, la edad del menor, la gravedad del ilícito, la forma de participación y considerando la idoneidad de la sanción que debe aplicarse se establece la pena de ...", no puede estimarse en caso alguno como suficiente para dar como satisfecha la obligación de atender a los criterios dejando constancia de ello, como tampoco lo sería meramente el enumerar uno o varios de los criterios, sin indicar por qué se prescinde de los demás y cómo inciden en la determinación de la sanción los criterios invocados ${ }^{64}$.

Cabe por tanto formular la pregunta, acerca de qué comportamiento del sentenciador sí podría dar por satisfecho el mandato. Una primera cuestión se refiere a la obligación de referirse a todos o algunos de los criterios. Esto depende esencialmente del caso concreto, pues sólo él determina cuáles de los criterios concurren en un particular supuesto juzgado. Sin embargo, parece poco razonable afirmar que ninguno de los criterios se encontrará presente en algún caso. Fuera de lo anterior, me remito a lo indicado precedentemente sobre la vinculación del juez al debate de las partes.

En segundo lugar, la sentencia debiera dar cuenta de qué criterios son los aplicables en el caso analizado y, enseguida, pronunciarse sobre ellos de acuerdo a los criterios de evaluación aquí mencionados en el análisis de los criterios en particular. Sean éstos vinculados al injusto o de orientación preventiva, obligación del juez es sopesar esos factores y explicitar en la sentencia de qué manera se les ha aplicado e interpretado. De esa forma es controlable que el juez haya ignorado algún criterio alegado por las partes y no se haya expresado, fundadamente, sobre las alegaciones que al respecto se hayan formulado. De lo contrario, del juego de

\footnotetext{
63 Horvitz/López, Derecho Procesal Penal chileno, T. II, Editorial Jurídica de Chile, Santiago, 2004, p. 419 ss.; Rieutord, Andrés, El recurso de nulidad en el nuevo proceso penal, Editorial Jurídica de Chile, Santiago, 2007, p. 66 ss.

${ }^{64}$ Sobre la necesidad de fundar la decisión en este ámbito y su vinculación con el principio de reserva legal vid. Rudnick Vizcarra, Carolina, La compensación racional de circunstancias modificatorias en la determinación de la pena, p. 89 ss.
} 
los artículos 24 LRPA, 374 e) y 342 d) del Código Procesal Penal se deduce un motivo absoluto de nulidad de la sentencia. Ello, considerando de esta forma que la norma del artículo 24 LRPA complementa, o explicita, el contenido del literal d) del artículo 342 del Código Procesal Penal.

Para ello debe considerarse como parte esencial de la sentencia definitiva al pronunciamiento sobre las cuestiones de determinación de pena. A ello se refiere el artículo 342 letra e) del Código Procesal Penal cuando indica la necesidad de expresar las razones legales o doctrinales que sirvieren para calificar jurídicamente cada uno de los hechos y sus circunstancias y para fundar el fallo (subrayado agregado). Si uno quisiera afirmar que el deber de fundamentación no alcanza a las cuestiones de determinación de pena, debiese entonces asignar a los razonamientos al efecto una naturaleza diferenciable, pero no es posible formular racionalmente tal diferencia. En efecto, las argumentaciones jurídicas que conducen a determinar la sanción son, en parte, fruto de las reflexiones que proceden del análisis de la parte expositiva de la sentencia y en tal sentido, no difieren de los razonamientos destinados a subsumir la conducta punible bajo normas penales concretas.

El artículo 24 LRPA es un reconocimiento expreso a esa circunstancia y por ello ineludible en esta materia. Cuestión distinta es el fundamento de la necesidad de fundar la decisión judicial. Ello está esencialmente vinculado con los presupuestos de corrección (richtigkeit) de un enunciado jurídico, los cuales son sólo evaluables en la medida que están fundados en razones ${ }^{65}$, razones que a su vez están sujetas a ciertos presupuesto argumentativos.

En tal sentido, la exigencia de fundamentación es más bien de carácter formal, en cuanto sólo da pie para exigir de la sentencia que explicite las razones que conducen a la decisión. Sobre si las razones utilizadas son correctas, es una cuestión independiente, la que se resuelve más bien en sede de la causal de infracción de derecho, que vendría a ser un nivel material del contenido, corrección, de las razones esgrimidas como fundamento de la decisión.

\section{b.2 La infracción de derecho}

Así como la falta de pronunciamiento corresponde a un vicio de la sentencia, no cualquier pronunciamiento fundado puede considerarse per se una determinación de pena adecuada a Derecho. En efecto, como se ha revisado al analizar cada uno de los criterios del artículo 24, existe un margen de argumentación y precisión de responsabilidad al interior de los parámetros. Pero una aplicación errónea de los parámetros puede dar igualmente sustento a una alegación de vicio de nulidad. Esta causal, presente también entre los motivos en

\footnotetext{
65 Neumann, Ulfried, Theorie der juristischen Argumentation, en: Kaufmann/Hassemer/Neumann (Eds.) Einführung in Rechtsphilosophie und Rechtstheorie der Gegenwart, p. 341 s.
} 
Medina - Sobre la determinación de pena y el recurso de nulidad...

que se podía fundar el recurso de casación ha sido, quizá por lo mismo, objeto de menor tratamiento y discusión ${ }^{66}$.

La infracción de derecho se verifica en los casos en que el juez no aplica, a un caso ya determinado en los hechos, una norma jurídica o la aplica incorrectamente, o bien que se recurre a una regla que no constituye una norma jurídica ${ }^{67}$. Del sólo tenor de las normas del Código Procesal Penal es posible vislumbrar la importancia que las cuestiones relacionadas a la determinación de pena tienen en la procedencia del recurso de nulidad.

No nos encontramos ya ante la hipótesis en la cual el sentenciador ignora su deber de fundar la determinación de pena, sino que en el razonamiento sobre la procedencia de un criterio o en la interpretación de éste, y sus consecuencias, se efectúa un razonamiento jurídico erróneo. Cierto es que esta causal será de compleja procedencia, dado que es previsible que en muchos casos se argumente en contra que ello no modifica el margen "discrecional" del tribunal para imponer pena, pero ello en nada obsta a la objeción conceptual por errónea aplicación del Derecho $^{68}$.

Por tanto, la pregunta fundamental aquí es ¿cuándo se ha aplicado una norma erróneamente? La respuesta a esa interrogante escapa el ámbito de una mera cuestión procesal y, en definitiva, se trata de la pretensión de corrección de un enunciado normativo, en el sentido que poder calificar determinados enunciados normativos bajo el par de correcto/incorrecto ${ }^{69}$. Esa cuestión se vincula directamente con el progresivo desarrollo de la teoría de la argumentación jurídica, especialmente de sus alcances en el campo de la aplicación de normas jurídicas a la resolución de $\operatorname{casos}^{70}$.

Por ello debe recordarse que la existencia de argumentación en la sentencia es sólo un presupuesto mínimo de racionalidad de la decisión, ya que satisfecho ese presupuesto debe analizarse que lo expuesto sea correcto, esto es, no sólo se

66 En ese sentido, e incluso considerando que esta causal "no presenta mayores complicaciones" vid. Duce/Riego, Proceso Penal, Editorial Jurídica de Chile, 2007, p. 518.

${ }^{67}$ Cfr. Volk, Klaus, Straprozeßrecht, 2a. Ed., Verlag C.H. Beck, Münich, 2001, \ 36, Rdn. 9 ss. Entre nosotros vid. Rieutord, Andrés, El recurso de nulidad en el nuevo proceso penal, p. 48.

68 Sobre la habitual reticencia a anular por esta causal invocando potestades facultativas vid. Cortez Matcovich, Gonzalo, El recurso de nulidad, Lexis Nexis, Santiago, 2006, p. 177 s.

69 Sobre la pretensión de corrección de los enunciados jurídicos, en contraposición a los de veracidad de los enunciados fácticos, vid. Habermas, Jürgen, Richtigkeit versus Wahrheit, Zum Sinn der Sollgeltung moralischer Urteile und Normen, en: del mismo, Wahrheit und Rechtfertigung, Suhrkamp, Frankfurt a.M., 1999, p. 271 ss.; Neumann, Ulfried, Wahrheit im Rechtm Zu Problematik und Legitimität einer fragwürdigen Denkform, Nomos VerlagBaden-Baden, 2004.

70 Los otros dos contextos, el de producción o establecimiento de normas jurídicas y el de la dogmática jurídica son aquí irrelevantes, vid. Atienz̧a, Manuel, Las Razones del Derecho, Teorías de la Argumentación Jurídica, Palestra Editores S.A.C., 2004, p. 28 s. 
trata de argumentar, sino de distinguir cuándo un argumento jurídico es correcto o más correcto que otro ${ }^{71}$.

Por ello las decisiones judiciales, como toda argumentación en el campo jurídico, están sometidas a determinadas reglas de justificación, externas e internas ${ }^{72}$, que incorporan tanto los criterios generales de lógica en la construcción de la argumentación jurídica, así como aquellas referencias necesarias a los criterios de interpretación de la ley, así como a las premisas dogmáticas elaboradas en la materia.

\section{b.3 La extensión de la revisión}

Cuán revisable, o anulable, es una sentencia por defectos vinculados a la determinación de pena es una cuestión discutible. En los extremos de las posibles respuestas a esta interrogante se encuentran, por un lado, la afirmación de una potestad meramente discrecional (arbitraria) que no permite revisión alguna, que ha sido en buena parte la línea argumental que ha seguido nuestra jurisprudencia.

Por el otro, quienes suscriben la teoría de la pena puntual (Punktstraftheorie) podrán afirmar casi en cualquier caso una errónea determinación de pena, dada la exactitud de la determinación pretendida y postulada por esta teoría ${ }^{73}$. El punto de partida se encuentra aquí en la aceptación de ciertos márgenes de discrecionalidad judicial, que sobre todo se pueden ver reflejados en la cuantía de la pena, más que en la clase de ésta. Aceptando que no existe una pena única y exacta que debe aplicarse al caso concreto.

Especial relevancia tiene el método comparativo de determinación de pena en caso de condena de múltiples partícipes, especialmente coautores ${ }^{74}$, de modo que las penas impuestas a todos ellos guarden la debida relación. En todo caso, la valoración de los distintos factores es una cuestión que no es factible cuantificar ex ante, sino que la praxis judicial debe desarrollar aplicaciones de los criterios a la luz de los distintos casos que se presenten, labor que sólo tiene sentido en la medida en que esa práctica pueda ser progresivamente uniformada por vía de la revisión judicial que permite el recurso de nulidad.

\section{b.4 La resolución de la nulidad}

El artículo 385 del Código Procesal Penal indica los casos en los cuales es procedente la declaración de nulidad de la sentencia, que a su vez habilitan al

\footnotetext{
71 Atienza, Manuel, Las razones del Derecho: Sobre la justificación de las decisiones judiciales, Isonomía, $\mathrm{N}^{\circ} 1,1994$, p. 63.

72 Alexy, Robert, Theorie der juristischen Argumentation, $3^{a}$ ed., Suhrkamp, Frankfurt a.M., 1996, p. 273 ss.

$73 \mathrm{NK} /$ Streng, \46, Rdn. 194.

74 NK/Streng, \46, Rdn. 193.
} 
Medina - Sobre la determinación de pena y el recurso de nulidad...

tribunal ad quem para dictar sentencia de reemplazo. Entre esos supuestos se encuentra la imposición de una pena superior a la que legalmente correspondiere. Los otros casos regulados por esa disposición se refieren a supuestos de errónea aplicación del derecho que se traducen en imperativos de absolución: calificación de delito de un hecho que no es tal y aplicación de pena cuando no correspondiere aplicar ninguna.

Asimismo, la disposición en comento se traduce en una restricción de la forma de resolver la nulidad en cuanto a vicios en la determinación de la pena. En caso de alegarse en perjuicio del condenado, pues la revisión por vía de nulidad no permite que en los casos de errónea aplicación del derecho que signifiquen la aplicación de una pena menor a la que corresponda se resuelva vía sentencia de reemplazo. Esta expresión del derecho al juicio previo ${ }^{75}$ se traduce en la obligación de realizar un nuevo juicio oral en los casos en que la infracción de derecho pudiese haber implicado una aplicación más gravosa de las reglas de determinación de pena.

Los consideraciones sobre determinación de pena que se han expuesto en el desarrollo de este trabajo se vinculan esencialmente al primer caso mencionado, esto es, la imposición de una pena superior a la que corresponde, pues los supuestos en que procede la absolución no se relacionan con el proceso de especificación de la sanción, sino con la pregunta previa de su procedencia.

Por ello, el campo fructífero de las reflexiones aquí expuestas se da en virtud de la posibilidad de revisión judicial de un fallo, cuando el sentenciador ha incurrido en una aplicación de las normas sobre la materia que, sin justificación racional bastante, imponen sanciones más altas que las que corresponde imponer. La fundamentación de tales recursos, así como de las sentencias que en ellos recaigan debiesen recoger lo aquí indicado sobre la forma de aplicar los distintos criterios de determinación de pena que establece el artículo $24 \mathrm{LRPA}^{76}$.

\footnotetext{
75 Horvitz/López, Derecho Procesal Penal chileno, T. II, p. 444.

${ }^{76}$ Así, por ejemplo, la I. Corte de Apelaciones de Temuco en sentencia de nulidad Rol Nº709-2007, de 20 de julio de 2007, que en su decisión de mayoría se refiere a la calificación del tribunal a quo respecto a la extensión del mal causado, considerando que el daño patrimonial verificado y la entidad de las lesiones son de una gravedad relativamente menor, por lo que no puede considerase ese criterios para la imposición de la sanción de internación en régimen cerrado, como asimismo no pueden estimarse, a efecto de la valoración de las circunstancias modificatorias, procesos previos en los cuales el menor ha sido sobreseído en virtud de falta de discernimiento, por lo que no existe reincidencia. Esas consideraciones llevan al tribunal, correctamente, a afirmar la errónea aplicación del derecho y, por consiguiente, a modificar la sanción impuesta.
} 


\section{Consideraciones finales}

Del análisis de la determinación de pena en el contexto de la LRPA pueden extraerse diversas conclusiones, las cuales pretenden un modelo más racional de decisión judicial sobre la materia.

En primer lugar, la determinación de pena en materia de responsabilidad penal adolescente constituye una materia relacionada con los criterios sobre el particular, aplicables al régimen general de responsabilidad penal, como queda demostrado ya en el hecho que los marcos penales de los delitos siguen siendo los mismos. Pero de la circunstancia que no sea un sistema totalmente autónomo, no se puede desprender una dependencia total, pues en el caso de infractores menores de edad, existen principios y valoraciones adicionales que considerar.

Ese régimen se caracteriza, en la práctica, por amplios campos de arbitrariedad, los cuales necesitan ser precisados, a fin de logar criterios racionales de control judicial en la materia y de justicia en la aplicación de las medidas que afectan la libertad y otros derechos. Así, a la determinación de pena subyace necesariamente un componente material, que está dado por la orientación que se le asigne, que en lo aquí propuesto debe vincularse a la sanción acorde a la responsabilidad culpable por el hecho punible, con todas sus particularidades.

Previo a la decisión sobre el control en la aplicación de los criterios del artículo 24 LRPA, se requiere la determinación del contenido de cada uno de los criterios, a fin de establecer el margen de plausibilidad argumentativa correspondiente. Esto es, la determinación de pena es un ejercicio fundado de aplicación de normas, guiado por reglas de argumentación jurídica que posibilitan la racionalidad de la decisión y su evaluación como correcta.

Pese a la praxis actual, la determinación de pena es un aspecto del ejercicio jurisdiccional en materia penal, susceptible de control por vía de recursos de derecho estricto. Ello sólo es así, en la medida en que las decisiones y alegaciones en la materia son fundadas, lo que hace posible su posterior examen de corrección. Los criterios del artículo 24 LRPA entregan los cauces por los cuales el legislador ha determinado que debe realizarse la correspondiente argumentación, que permite dar cuenta del disvalor del injusto penal, cuyas características específicas no pueden ser recogidas por los tipos abstractos de la ley penal y que las reglas generales de determinación de pena no pueden captar en su carácter único.

Ello es determinante tanto para la elección de la sanción, así como para el establecimiento de su magnitud. Que se establezca la posibilidad de múltiples sanciones, no significa que el juez puede resolver a su capricho sobre la aplicación de una cualquiera. Sólo la argumentación que de cuenta de qué clase de expresión del injusto se ha verificado en el caso concreto permite una elección fundada. Lo mismo vale para la fijación de la entidad de la sanción, pues los amplios márgenes que nuestra ley contempla, sólo pueden significar que en la división de funciones 
Medina - Sobre la determinación de pena y el recurso de nulidad...

entre legislador y juez, una parte significativa de la concreción de la sanción penal está entregada al órgano jurisdiccional: esta división no conlleva en caso alguno la entrega de una facultad discrecional incontrolable.

Asimismo, la determinación de pena en la LRPA puede ser, en esa medida, objeto de control vía recurso de nulidad. Para ello dos son las vías preeminentes: (i) el control por falta de fundamentación de la sentencia y (ii) por vulneración del derecho. Ambos aspectos no son sino aspectos sucesivos de la necesaria expresión de racionalidad de la sanción aplicada. La infracción de derecho no puede ser revisada, sino en la medida en que las argumentaciones que subyacen han sido expresadas. Pero la sola expresión de las argumentaciones es condición necesaria pero no suficiente de la racionalidad en la determinación de la pena. El juez no está dotado de una facultad incontrolable en la materia, sino que las discordancias fundadas con el razonamiento judicial son suficientes para la revisión de la sentencia.

Estas reflexiones sobre una materia de trascendencia ineludible en el campo del derecho penal nacional, sólo demuestran una vez más los largos caminos que nuestra dogmática aún debe recorrer para la racionalización de nuestra práctica jurídica. Sirva ello de demostración de la necesidad de continuar con el legado de Juan Bustos en la senda de la reflexión profunda sobre las materias de nuestra disciplina. 